\title{
Aerobic bacteriological studies on the respiratory tracts of apparently healthy and pneumonic camels (Camelus dromedaries) in selected districts of Afar Region, Ethiopia
}

\author{
Mu'uz Gebru $^{1} \cdot$ Genene Tefera $^{2} \cdot$ Fufa Dawo $^{3} \cdot$ Tesfaye Sisay Tessema $^{4}$ (D)
}

Received: 21 October 2016 / Accepted: 9 November 2017 / Published online: 16 November 2017

(C) Springer Science+Business Media B.V., part of Springer Nature 2017

\begin{abstract}
A cross-sectional study was conducted to isolate and identify bacterial species from the respiratory tract of apparently healthy and pneumonic camels in Asayita and Dubti woredas in the Afar Region, Ethiopia. From a total of 74 lung tissue and 74 tracheal swab samples Staphylococcus aureus, $16.3 \%$, Streptococcus equi subsp. equi, $13.0 \%$, and Pasteurella multocida, $10.9 \%$, were dominant isolates from pneumonic lungs; Escherichia coli, 12.7\%, Proteus species, $10.9 \%$, and Klebsiella pneumoniae, $9.1 \%$, were the majority in the normal lungs. The majority of the isolates colonized both anatomical sites investigated. There was a statistically significant association between the health status of the camels as well as the anatomical site studied with the isolation rates of the major respiratory pathogens $(p<0.05)$. Furthermore, the isolates were susceptible to norfloxacin, streptomycin, and gentamicin but resistant to ampicillin and tetracycline on in vitro test. Further studies on the pathogenicity of the major isolates are recommended.
\end{abstract}

Keywords Afar - Antibiotic susceptibility · Bacterial . Camel $\cdot$ Lungs

Tesfaye Sisay Tessema

Tesfu74@yahoo.com

1 School of Veterinary Medicine, Semera University, P.O. Box 132, Semera, Ethiopia

2 Institute of Biodiversity Conservation, P.O. Box 30726, Addis Ababa, Ethiopia

3 College of Veterinary Medicine Agriculture, Addis Ababa University, P.O. Box 34, Debre Zeit, Ethiopia

4 Institute of Biotechnology, Addis Ababa University, P.O. Box 1176, Addis Ababa, Ethiopia

\section{Introduction}

Generally, camels are assumed to be well adapted to their environment and resist infectious diseases that inflict other livestock species in the same region; however, a number of economically important diseases affect camels (Alharbi 2016). Recently, respiratory tract diseases have emerged among camels worldwide causing considerable loss of life and production (Funk et al. 2016; Ali et al. 2017).

Camel respiratory problem is an emerging disease in Ethiopia causing extensive loss of production and deaths with limited efforts to study the causative agents (Bekele 2008). Outbreaks have been reported in 1995 in the Afar region (Roger et al. 2000; Roger et al. 2001), in 2005/2006 in the Afar and Oromia regions (Wernery et al. 2006), in the Somali and Oromia regions, as well as in 2011 in Afar region in the country. A definitive etiology of the problem has not yet been conclusively determined though previous reports indicate the involvement of peste des petits ruminant (PPR)-like virus, Streptococcus equi subsp. equi, Pasteurella, Mannheimia, and Mycoplasma species (Yigezu et al. 1997; Roger et al. 2001). Despite some efforts made far, there was no substantial result obtained from the investigation of the disease. More investigative efforts are still in need for the identification of the true cause of the problem so as to design sustainable control strategies.

Streptococcus species have been isolated from clinically healthy camels although they were not definitely identified and characterized. Besides, Streptococcus species have been isolated from active respiratory disease of camels (Wareth et al. 2014). But there is no data on the isolation of $S$. equi subsp. equi from camels.

Therefore, the present study was conducted to determine comparatively the bacterial species associated with camels with and without pneumonic lungs, identify the Streptococci spp. prevalent in camel respiratory tract, as well as determine 
the antibiotic sensitivity pattern of the leading bacterial agents recovered from camels with pneumonic lungs.

\section{Materials and methods}

\section{Study area and population}

The study was conducted in selected pastoral and agropastoral residences of Asayita and Dubti Districts of Afar national regional state (ANRS), located in northeast part of Ethiopia (Fig. 1). Animal husbandry in the region is characterized by extensive pastoral production system and seasonal mobility due to the shortage of rainfall. The camel population of Asayita and Dubti Districts are about 3277 and 5966, respectively (CSA 2004).
Dubti Woreda is about $610 \mathrm{~km}$ northeast of Addis Ababa, the capital city of Ethiopia, at $11^{\circ} 49^{\prime} 59.99^{\prime \prime} \mathrm{N}$ and $41^{\circ} 00^{\prime} 0.00^{\prime \prime} \mathrm{E}$, with an average elevation of $503 \mathrm{~m}$ above sea level (masl) and high temperature which ranges from 25 to $42{ }^{\circ} \mathrm{C}$. May-June is the driest season of the year; the main rainy season is from July to September. Asayita Woreda is about $667 \mathrm{~km}$ northeast of Addis Ababa, at $11^{\circ}$ $34^{\prime} \mathrm{N}$ and $41^{\circ} 26^{\prime} \mathrm{E}$.

The study population included camels slaughtered in the study areas during the study period. In the region, all camels were kept under extensive pastoral and agro-pastoral production conditions. Nearly all of the slaughtered camels were adult males and clinically healthy during antemortem examination. The community in the area keeps a higher proportion of breeding females and few males for mating and transportation. The owners release adult camels ( $>2$ years) for browsing to the field during the day time;
Fig. 1 Administrative location of Afar region in the country showing the study zone and woredas

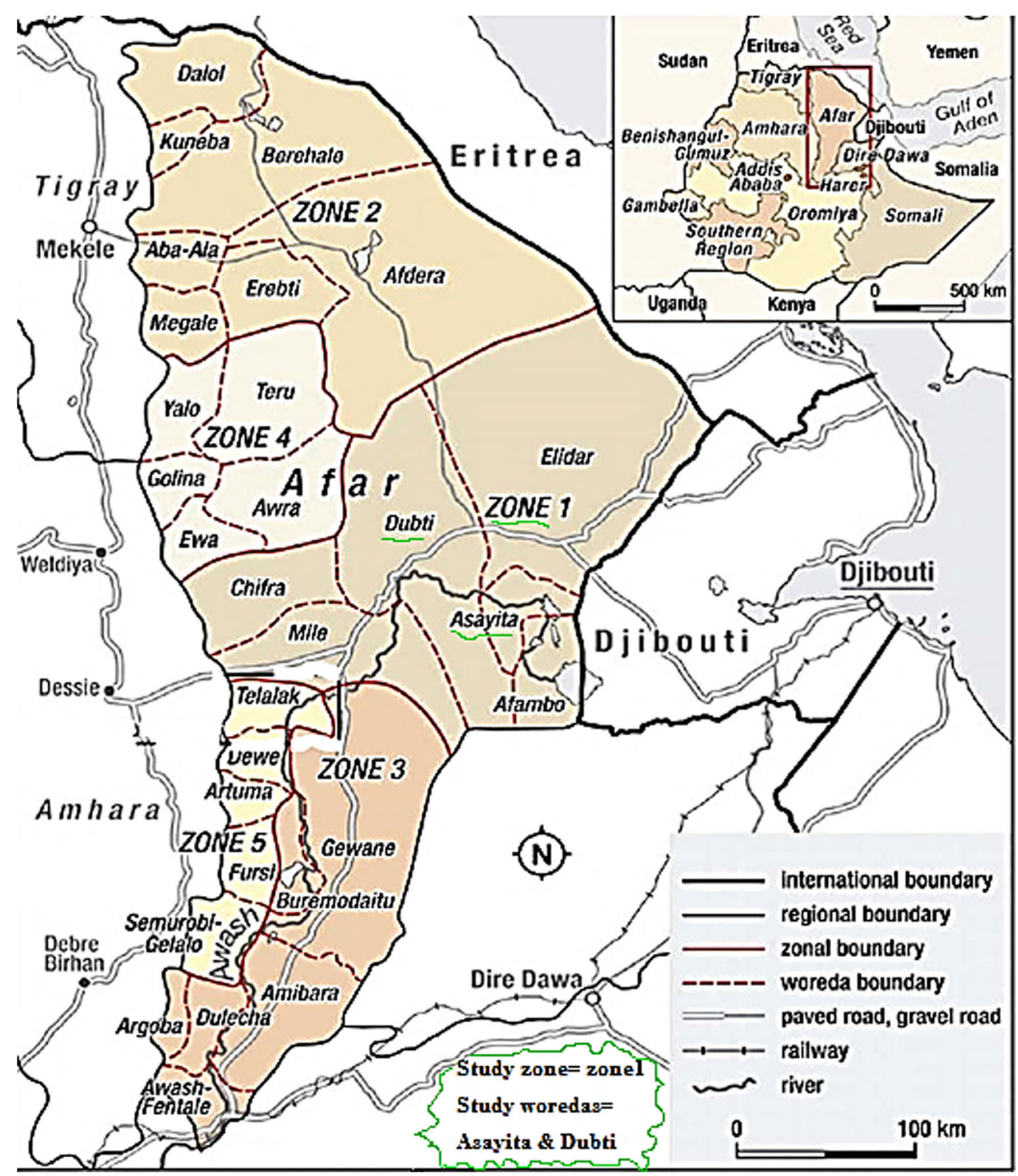


however, young camels $(<2$ years) are kept in a confined and fenced area around the homesteads.

\section{Study design and sample size}

A cross-sectional study was conducted in Dubti and Asayita woredas. These areas were chosen conveniently based on access to transport to conduct the laboratory analysis of collected samples at samara veterinary regional laboratory and due to previous reports of camel respiratory infection outbreaks in the areas. A total of ten kebelles (pastoral associations (PAs)) were selected from the two woredas (five PAs from each woreda). The PAs were selected purposively based on accessibility to the villages by vehicle or proximity to road, previous and existing report of camel respiratory problems, and awareness of the society and size of the camel population.

However, as the number of slaughtered camels was so small, only 74 camels were used in the study. Consequently, 46 and 28 lungs together with their analogous trachea were sampled from Dubti and Asayita, respectively.

\section{Sample collection}

The procedures followed by Tesfaye et al. (2013) were used in collecting and processing samples for isolation and identification of bacterial spp. Ante-mortem and post-mortem examinations were carried out to identify animals and/or lungs with respiratory problems using clinical examination before slaughter and visualization, palpation and incision methods after slaughter. Afterwards, tracheal swabs and lung tissue samples were collected.

\section{Isolation and identification of bacterial species}

After $24 \mathrm{~h}$ of incubation in broth, the cultures were mixed; a loopful of the culture was streaked over a $7 \%$ sheep blood agar (Oxide, Hampshire, England) and incubated aerobically at $37^{\circ} \mathrm{C}$ for 24 to $72 \mathrm{~h}$.

Single colony from each type of the observed colonies was sub-cultured on blood agar plates. The pure cultures were processed by Gram's staining; Gram-negative bacteria were sub-cultured on MacConkey agar plates (Oxide, Hampshire, England) for further characterization. Primary identification of the bacteria was performed using colony morphology, Gram reaction, cellular morphology, catalase and oxidase tests, and growth on MacConkey agar. Final identification was carried out by subjecting pure cultures of single colony type into a series of secondary biochemical tests, namely, methyl-red, indole, citrate utilization, coagulase, motility, TSI, esculin hydrolysis, as well as sugar fermentation tests, as required for each bacterial spp. considered. In addition, growth characteristics on mannitol salt agar and Edward's medium were used for identification of Staphylococci and Streptococci spp., respectively. All the tests were conducted following standard procedures.

\section{Fatty acid analysis using Biolog-Microstation identification system}

Pure isolates of Streptococcus species were prepared for Biolog-Microstation identification system (Biolog, California, USA), at the Institute of Biodiversity Conservation, Addis Ababa, Ethiopia, which is a bacterial identification technique based on surface fatty acid substrates of each microbial species. The colonies of Streptococcus species were inoculated on the Biolog Universal Growth (BUG) agar with 5.0\% sheep blood and incubated at $37^{\circ} \mathrm{C}$ for $24 \mathrm{~h}$. Sub-culturing was done using the same culture media to have pure culture colonies before identification was done by Omnilog.

Bacterial suspension was prepared from the grown pure culture colonies with an appropriate level of bacterial density (20.0\% turbidity in 16-18 inoculating fluid), as recommended in the protocol of the instrument. The suspension was inoculated in to Biolog micro plates aseptically. Then, the micro plates were loaded in to the Omnilog and incubated at $37{ }^{\circ} \mathrm{C}$ for $24 \mathrm{~h}$ after the necessary information regarding the bacteria was registered on the software of the instrument. Finally, the micro plates were read by the Omnilog identification system and the bacterial species were identified using the inbuilt Biolog database.

\section{Antibiotic susceptibility testing}

Antibiotic susceptibility tests were conducted on the representative isolates of the dominant bacterial spp. isolated following disk diffusion method using Oxoid antibiotic disks, namely, ampicillin, erythromycin, kanamycin, norfloxacin, tetracyclin, chloramphenicol, streptomycin, gentamicin, vancomycin, and doxycyclin. The bacterial isolates were cultivated on a blood agar to obtain fresh culture. Three to five identical colonies were harvested and transferred to a tube containing 4-5 ml sterile distilled water. The suspension was mixed gently until turbidity corresponding to $0.5 \mathrm{McF}$ arland standard was reached to obtain a homogeneous suspension and then poured onto Mueller-Hinton agar plate (Oxoid, Hampshire, England). Seven percent sheep blood was used for streptococcus species (Janosi and Kaszanyitzki 2003). After the inoculum on the plate was dried, antibiotic disks were distributed over the surface of the inoculated plates at equal distance from each other using sterile forceps. The disks were gently pressed onto the agar to ensure firm contact and then incubated for $24 \mathrm{~h}$ at $37^{\circ} \mathrm{C}$.

After $24 \mathrm{~h}$, the diameters of the zones of complete inhibition around the disks were measured from the back of the plate to the nearest whole millimeter using a millimeter-gauged ruler. Zone margins were read as areas showing no obvious 
growth detected by the unaided eye. It was read again after $48 \mathrm{~h}$ of incubation if the isolates were not sufficiently grown. Every test was conducted twofold, and then an average of the two results was taken as a final result. Growth inhibition zones were interpreted according to the manufacturer's recommendation.

\section{Data analysis}

The data were analyzed using SPSS ${ }^{\circ}$ Version 17.0 software. The results generated from the study were summarized using descriptive statistics. Percentages were used to express the relative abundance of each genera/species to the total number of isolates. Furthermore, chi-square test was computed so as to observe the relationship between the variants. A $p$ value of $<0.05$ was considered indicative of a statistically significant difference.

\section{Results}

\section{Bacterial species isolated from the trachea and lungs of camels}

Twenty six (35.1\%) of the lungs possessed one or more types of lesion. The remaining 48 (64.9\%) of the lungs had no evidence of gross pathological lesion. The collected tracheal swabs and lung tissue samples were processed for aerobic bacteriological isolation and characterization.

Accordingly, only 39 (52.7\%) of the lung tissue samples and $33(44.6 \%)$ of the tracheal swabs yielded bacterial colonies. The remaining 4 (5.4\%) of the lung lesions, 31 (41.9\%) of the apparently healthy lungs, and $41(55.4 \%)$ of the tracheal samples examined did not reveal any bacterial growth. More than one bacterial species were isolated from $20(27.0 \%)$ pneumonic lungs, $6(8.1 \%)$ apparently healthy lungs, and 18 (24.3\%) tracheal samples. On the other hand, only one bacterial isolate was identified from $2(2.7 \%)$ pneumonic lungs, 11 (14.9\%) apparently healthy lungs, and 15 (20.3\%) tracheal samples investigated.

\section{Isolation rates of bacterial species is associated with presence of pneumonic lesions}

A total of 262 bacterial isolates were identified from 74 lung and 74 corresponding tracheal samples; out of which 115 $(43.9 \%)$ and $147(56.1 \%)$ were recovered from the trachea and lung, respectively.

Totally, 92 bacteria were isolated from the pneumonic camel lungs from which $S$. aureus, 15 (16.3\%), S. equi subsp. equi, 12 (13.0\%), and P. multocida, 10 (10.9\%), were the dominant isolates. S. equi subsp. zooepidemicus and
S. pneumoniae were recovered at the lowest rate; each comprised $1 \%$ (Table 1).

E. coli and Proteus species accounted for 7 (12.7\%) and 6 (10.9\%), respectively, among 55 bacterial isolates demonstrated from the healthy lungs. On the other side, S. equi subsp. equi, B. bronchiseptica, and P. aeruginosa, each 1 (1.8\%), were isolated at the lowest proportion. M. haemolytica was not recovered from the normal lungs.

There was a statistically significant difference between the isolation rates of $S$. equi subsp. equi, P. multocida, M. haemolytica, B. bronchiseptica, S. aureus, and $K$. pneumonia and the health status of the lung $(p<0.05)$, but no difference was observed for the above isolates of the trachea samples in relation to the health status of the corresponding lungs $(p>0.05)$.

Among 262 bacterial isolates recovered from the lungs and trachea, the majority colonized both the anatomical sites investigated although differently (Fig. 2). However, a general decrease in the isolation rate of the normal flora and increase in isolation of potential respiratory pathogens, namely, S. equisubsp. equi, P. multocida, M. hemolytica, and $S$. pneumonia, was observed in the lungs than the trachea. There was a statistically significant difference between the anatomical sites examined with the isolation rate of the major respiratory pathogens (except $B$. bronchiseptica) $(p<0.05)$.

Generally, the present study showed that the isolation frequency of the major respiratory pathogenic bacteria was higher in lungs with different lesions than clinically normal lungs. On the other hand, the normal bacterial flora was more prevalent in the respiratory passage ways of apparently healthy camels than the pneumonic ones. Besides, there was a statistically significant difference between pneumonic and apparently healthy camels with the isolation rate of the major respiratory pathogens (except $B$. bronchiseptica and K. pneumoniae) $(p<0.05)$ (Fig. 3).

\section{Antibiotic sensitivity pattern of bacterial isolates}

The antibiogram of the isolates studied indicated that the S. equi subsp. equi isolates were found to be sensitive to vancomycin (100.0\%), norfloxacin $(94.1 \%)$, erythromycin $(58.8 \%)$, gentamicin $(52.9 \%)$, and ampicillin $(52.0 \%)$. Most of the isolates of P. multocida have shown a high level of sensitivity to gentamicin, streptomycin, norfloxacin, and chloramphenicol. Most of the isolates of M. haemolytica were sensitive to streptomycin, kanamycin, gentamicin, and norfloxacin (Table 2).

\section{Discussion}

The respiratory tract of apparently healthy animals acted as a reservoir for many species of microorganisms that reached the 
Table 1 Bacterial species isolated from the trachea and lung samples of camels

\begin{tabular}{|c|c|c|c|c|c|c|}
\hline \multirow[t]{2}{*}{ Bacterial species } & \multicolumn{3}{|l|}{ Trachea } & \multicolumn{3}{|l|}{ Lung } \\
\hline & Healthy & Pneumonic & Total & Healthy & Pneumonic & Total \\
\hline S. aureus & $3(4.5 \%)$ & $5(10.2 \%)$ & $8(7.0 \%)$ & $4(7.5 \%)$ & $15(16.3 \%)$ & $19(12.9 \%)$ \\
\hline S. equi subsp. equi & $0(0.0 \%)$ & $0(0.0 \%)$ & $0(0.0 \%)$ & $1(1.8 \%)$ & $12(13.0 \%)$ & $13(8.8 \%)$ \\
\hline P. multocida & $0(0.0 \%)$ & $1(2.0 \%)$ & $1(9.0 \%)$ & $4(7.3 \%)$ & $10(10.9 \%)$ & $14(9.5 \%)$ \\
\hline Corynebacterium spp. & $0(0.0 \%)$ & $1(2.0 \%)$ & $1(9.0 \%)$ & $2(3.6 \%)$ & $10(10.9 \%)$ & $12(8.2 \%)$ \\
\hline M. haemolytica & $0(0.0 \%)$ & $0(0.0 \%)$ & $0(0.0 \%)$ & $0(0.0 \%)$ & $8(8.7 \%)$ & $8(5.4 \%)$ \\
\hline K. pneumoniae & $8(12.1 \%)$ & $1(2.0 \%)$ & $9(7.8 \%)$ & $5(9.1 \%)$ & $8(8.7 \%)$ & $13(8.8 \%)$ \\
\hline$C N S$ & $9(13.6 \%)$ & $4(8.2 \%)$ & $13(11.3 \%)$ & $2(3.6 \%)$ & $5(5.4 \%)$ & $7(4.8 \%)$ \\
\hline P. aeruginosa & $0(0.0 \%)$ & $1(2.0 \%)$ & $1(9.0 \%)$ & $1(1.8 \%)$ & $5(5.4 \%)$ & $6(4.1 \%)$ \\
\hline E. coli & $7(10.6 \%)$ & $13(26.5 \%)$ & $20(17.4 \%)$ & $7(12.7 \%)$ & $5(5.4 \%)$ & $12(8.2 \%)$ \\
\hline B. bronchiseptica & $2(3.0 \%)$ & $0(0.0 \%)$ & $2(1.7 \%)$ & $1(1.8 \%)$ & $4(4.3 \%)$ & $5(3.4 \%)$ \\
\hline Proteus spp. & $0(0.0 \%)$ & $0(0.0 \%)$ & $0(0.0 \%)$ & $6(10.9 \%)$ & $3(3.3 \%)$ & $9(6.1 \%)$ \\
\hline Bacillus spp. & $7(10.6 \%)$ & $3(6.1 \%)$ & $10(8.7 \%)$ & $5(9.1 \%)$ & $3(3.3 \%)$ & $8(5.4 \%)$ \\
\hline S. pneumoniae & $0(0.0 \%)$ & $0(0.0 \%)$ & $0(0.0 \%)$ & $4(7.3 \%)$ & $1(1.1 \%)$ & $5(3.4 \%)$ \\
\hline S. equisubsp. zooepidemicus & $7(10.6 \%)$ & $1(2.0 \%)$ & $8(7.0 \%)$ & $3(5.5 \%)$ & $1(1.1 \%)$ & $4(2.7 \%)$ \\
\hline Micrococcus spp. & $4(6.1 \%)$ & $3(6.1 \%)$ & $7(6.1 \%)$ & $4(7.3 \%)$ & $0(0.0 \%)$ & $4(2.7 \%)$ \\
\hline Neisseria spp. & $6(9.1 \%)$ & $2(4.1 \%)$ & $8(7.0 \%)$ & $0(0.0 \%)$ & $0(0.0 \%)$ & $0(0.0 \%)$ \\
\hline Enterococcus spp. & $1(1.5 \%)$ & $1(2.0 \%)$ & $2(1.7 \%)$ & $0(0.0 \%)$ & $0(0.0 \%)$ & $0(0.0 \%)$ \\
\hline Other Streptococcus spp. & $5(7.6 \%)$ & $2(4.1 \%)$ & $7(6.1 \%)$ & $2(3.6 \%)$ & $0(0.0 \%)$ & $2(1.4 \%)$ \\
\hline Unidentified spp. & $7(10.6 \%)$ & $11(22.4 \%)$ & $18(15.7 \%)$ & $4(7.3 \%)$ & $2(2.2 \%)$ & $6(1.4 \%)$ \\
\hline Total & $66(100.0 \%)$ & $49(100.0 \%)$ & $115(100.0 \%)$ & $55(100.0 \%)$ & $92(100.0 \%)$ & $147(100.0 \%)$ \\
\hline
\end{tabular}

CNS, coagulase-negative Staphylococci

nasal cavity through various ways. This study has shown that a wide variety of bacterial species colonize the respiratory passageways of camels in the study area. This is supported by several researchers who previously demonstrated diverse bacterial species from various regions of the camel respiratory tract: nasal tracts, tonsil, trachea and lungs (Ismail et al. 2014; Wareth et al. 2014), and normal and pneumonic lungs (Wareth et al. 2014; Ahmed and Musa 2015).

The consistent isolation of these organisms from the pneumonic lungs of various species of animals might indicate their role in causing different respiratory infections especially when the immune system of the animal is compromised by some other external factors. The normal bacterial flora of a healthy individual can be altered by several factors such as changes in the hygienic condition, environmental and climatic conditions, and nutritional and immunological status of the animal. Such factors could lower the resistance of the lung tissue and the existing organism most probable would get the upper hand, leading to the presentation of a variety of pathologies (Bosch et al. 2013).
Fig. 2 Relative proportions of the bacterial isolates in relation to sampling tissues

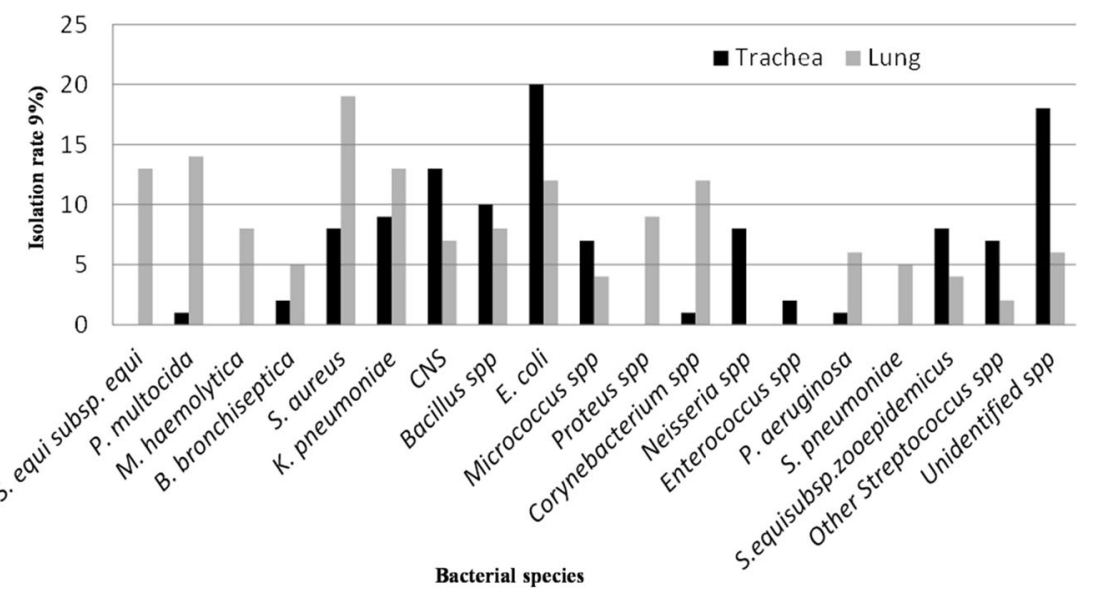


Fig. 3 Bacterial species isolated from the respiratory passageways of apparently healthy and pneumonic camels

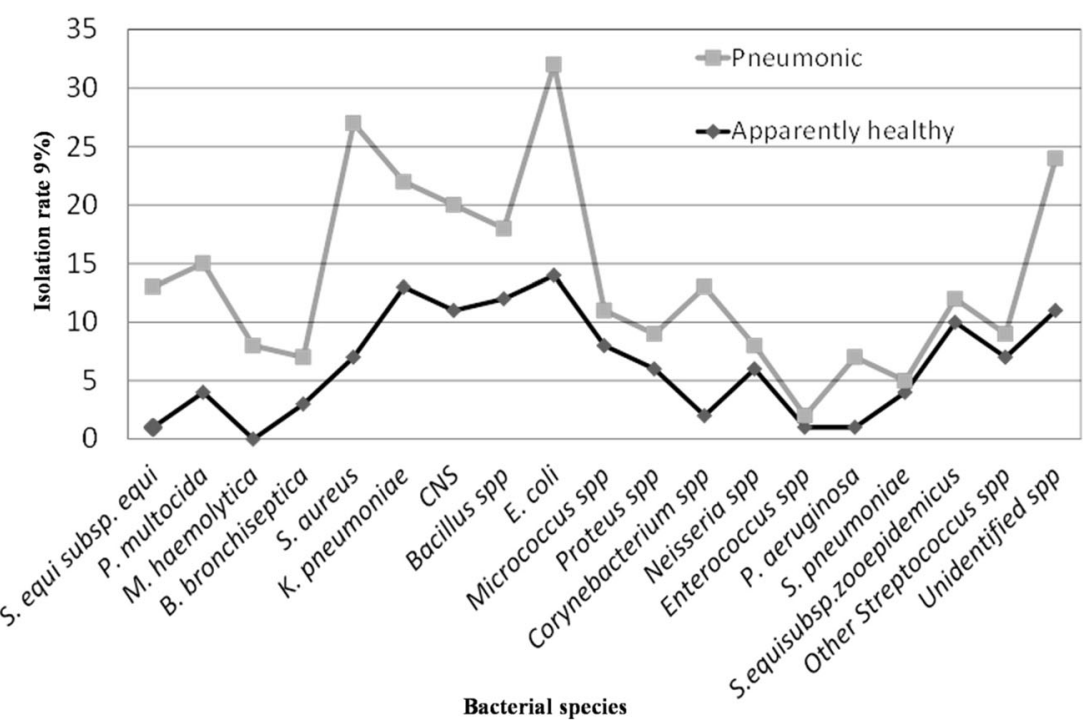

The current study revealed that the majority of the isolated bacteria colonize both anatomical sites and a general increase in the isolation rate of the pathogenic bacteria as one goes down the respiratory tract (Fig. 2). The normal bacterial flora was more prevalent in the respiratory passage ways of apparently healthy than the pneumonic camels. This is quite suggestive of the accepted idea that these organisms live as a commensal in the upper respiratory tract, invading the lung under conditions of stress. Stress factors have been reported to suppress the mucocilliary clearance mechanism and the overall respiratory defensive system which allows the proliferation of bacterial commensals in the respiratory tract and an abrupt shift from commensal to pathogen (Caswell 2014). Similar trend of bacterial distribution was also observed by Azizollah et al. (2009) and Al-Tarazi (2001) during their bacteriological studies on the respiratory tracts of camels.
Considering the stress of weather, disease, and poor management conditions to which the camels are constantly subjected to in the study area, the pathogenic role of several bacterial species that inhabit the upper respiratory tract of apparently normal camels could be enormous. Therefore, S. equi subsp. equi, M. haemolytica, P. multocida, $K$. pneumoniae, S. aureus, and B. bronchiseptica are described as normal inhabitants of upper respiratory tract as well as causative agents of pneumonia during stressful conditions. In line with this, these bacteria were also isolated at a higher incidence rate from the pneumonic lungs in the present investigation. The pathogenic bacteria isolated during the present study period are comparable to those previously reported from the respiratory tract of apparently healthy camels (Ahmed and Musa 2015).

Most species of the genus streptococcus are considered potential pathogens, occur in nature, and some are commensal

Table 2 Antibiotic susceptibility profiles of bacterial isolates from the respiratory tracts of camels based on the readings on disk diffusion method

\begin{tabular}{|c|c|c|c|c|c|c|c|c|c|c|c|}
\hline \multirow[t]{2}{*}{ Bacterial species } & \multirow[t]{2}{*}{$N$} & \multicolumn{10}{|c|}{$\%$ of isolates sensitive to the antibacterial agents } \\
\hline & & AMP & $\mathrm{E}$ & $\mathrm{K}$ & NOR & $\mathrm{TE}$ & $\mathrm{C}$ & $\mathrm{S}$ & $\mathrm{CN}$ & VA & DO \\
\hline P. multocida & 12 & 25.0 & 50.0 & 58.3 & 75.0 & 16.7 & 75.0 & 75.0 & 83.3 & 33.3 & 41.7 \\
\hline M. haemolytica & 11 & 27.2 & 45.5 & 81.8 & 72.3 & 9.1 & 63.6 & 90.9 & 90.9 & 18.2 & 36.4 \\
\hline B. bronchoseptica & 10 & 40.0 & 50.0 & 30.0 & 90.0 & 20.0 & 70.0 & 100.0 & 80.0 & 10.0 & 60.0 \\
\hline K. pneumoniae & 11 & 0.0 & 72.7 & 9.1 & 100.0 & 0.0 & 18.2 & 100.0 & 100.0 & 9.1 & 81.8 \\
\hline S. equi subsp. equi & 17 & 52.0 & 58.8 & 35.3 & 94.1 & 41.2 & 29.4 & 17.6 & 52.9 & 100.0 & 47.1 \\
\hline S. pneumoniae & 5 & 0.0 & 80.0 & 0.0 & 100.0 & 20.0 & 40.0 & 80.0 & 40.0 & 100.0 & 60.0 \\
\hline S. aureus & 9 & 33.3 & 77.7 & 66.6 & 100.0 & 44.4 & 11.0 & 22.2 & 88.8 & 100.0 & 33.3 \\
\hline P. aeruginosa & 10 & 10.0 & 70.0 & 50.0 & 90.0 & 20.0 & 40.0 & 100.0 & 90.0 & 0.0 & 60.0 .0 \\
\hline E. coli & 8 & 50.0 & 37.5 & 62.5 & 100.0 & 25.0 & 87.5 & 100.0 & 100 & 12.5 & 75.0 \\
\hline Proteus & 9 & 22.2 & 44.4 & 0.0 & 33.3 & 11.1 & 44.4 & 22.2 & 77.7 & 55.5 & 88.9 \\
\hline
\end{tabular}

$N$, number of isolates tested; $A M P$, ampicillin; $E$, erythromycin; $K$, kanamycin; $N O R$, norfloxacin; $T E$, tetracyclin; $C$, chloramphenicol; $S$, streptomycin; $C N$, gentamicin; $V A$, vancomycin; $D O$, doxycyclin 
in the respiratory, genital, and alimentary tracts and skin of animals and man (Parks et al. 2015). Streptococcus species have been isolated from clinically healthy camels although they were not definitely identified and characterized (Azizollah et al. 2009). On the other hand, Streptococcus species such as $\beta$-haemolytic Streptococci, $S$. viridans, $S$. pneumoniae, and S. pyogenes were described in active respiratory disease of camels elsewhere (Wareth et al. 2014; Ahmed and Musa 2015). Yigezu et al. (1997) have reported the bacteria from camel lungs and suggested its role in the epizootic occurring in camels in Ethiopia. In the present work, S. equi subsp. equi was recovered from the lungs of camels, at a much higher rate in pneumonic lungs compared to healthy ones, but was not from the trachea. This could suggest low level occurrence of the organism as normal flora and involvement in camel pneumonia under optimum conditions. Therefore, the bacteria could be considered as one of the important players in camel respiratory infections.

Streptococcus equi subsp. equi has been identified as the causative agent in equine strangles. The agent is directly transmissible via oral or nasal routes and by indirect means through contamination of the environment by excretions from sick horses. Regrouping of horses is usually a risk factor in a strangles outbreak (Yigezu et al. 1997). Although the camel rearing areas of Asayita and Dubti are uninhabited by horses, they are inhabited by donkeys and used as pack animals; this could favor the transmission of the agent by contact.

Pasteurella species reside as commensals on the mucosa of the upper respiratory of diverse animal species and play a role as a primary or secondary agent in pneumonia (Poliquin et al. 2015). The isolation rate of Pasteurella multocida from the pneumonic camel lung (10.9\%) was higher than that of healthy lungs (7.3\%). Abubakar et al. (2008) have also demonstrated P. multocida at a rate of $4.4 \%$ from pneumonic lungs of camels in Nigeria but failed to isolate it from normal lungs. The recovery rate of the bacteria from lung lesions in the present work is higher compared to that of previous reports from camels (Abubakar et al. 2008; Wareth et al. 2014), sheep (Merga et al. 2006), and goats (Demissie et al. 2014). This discrepancy might be attributed to the variation in sample size, difference in agro-ecological zones of study areas, and host species diversity as well as health status of the study animals.

Mannheimia haemolytica are commensals, residing in the nasopharyngeal micro flora and are all capable of causing infection when the body defense mechanisms are impaired (Caswell 2014) although mainly in ruminants. $M$. haemolytica was isolated at a high rate from the lungs of clinically diseased camels in this study; the isolation rate from pneumonic lungs $(8.7 \%)$ is to a great extent higher than the report of Desissa et al. (2009), 0.5\% from donkeys, and Abubakar et al. (2008), $0.3 \%$ from camels. However, the finding is consistent with that of Al-Tarazi (2001), who found $6.6 \%$ from pneumonic lungs of camels in Jordan. Much higher rates have been reported from ovine pneumonic lungs (Demissie et al. 2014) and lungs of healthy goats (Merga et al. 2006). These bacteria were not isolated from the trachea and apparently normal lungs. The occurrence of M. haemolytica in higher proportion in the clinically ill camels can make the bacteria to be considered as one of the major factors for occurrence of camel respiratory disease complex.

$K$. pneumoniae was recovered at an enormously comparable frequency from the pneumonic and healthy lungs (Table 1); this is comparable with that of Al-Doughaym et al. (1999) from the lungs of pneumonic camels, $10.9 \%$. Higher isolation rates were reported by Wareth et al. (2014), 26.7\%, and Azizollah et al. (2009), 25.0\%. K. Pneumoniae has been reported from the respiratory tracts of diverse animal spp. such as donkeys (Desissa et al. 2009), at higher rate from donkeys having respiratory problems. Lower figures have also been reported by Abubakar et al. (2008), 6.3\%, from Nigerian camel lungs and Ismail et al. (2014) from Egypt. B. bronchiseptica has been reported by Nesibu et al. (2010) at a rate of $3.5 \%$ from the pulmonary lesions of camels compared to the current isolation rate, $4.3 \%$. In addition to this it has been also isolated from the trachea $(3.0 \%)$ and lung $(1.8 \%)$ of apparently healthy camels. Ahmed and Musa (2015) reported a lower rate $(0.1 \%)$.

Staphylococcus aureus is known to occur as a commensal on the skin, the nose, and mucous membranes of healthy humans and animals and also an opportunistic pathogen in multiple infectious diseases (Lozano et al. 2016). In this study, $S$. aureus was the commonest bacteria in the pneumonic lungs, $16.3 \%$, which is higher when compared the report of Al-Tarazi (2001), 10.6\%, from lung lesions of camels. Higher isolation rates were reported by Wareth et al. (2014), 37.1\%, and Al-Doughaym et al. (1999), 24.8\%, from pneumonic camel lungs. Ismail et al. (2014) and Azizollah et al. (2009) also recovered higher rates, 14.5 and $14.0 \%$, respectively, of $S$. aureus from lungs of apparently healthy camels. The present and previous data suggest that the bacteria reside as a normal inhabitant of upper respiratory tract and possibly as a causative agent of secondary pneumonia.

The failure to isolate bacteria from four lung tissues with lesions might be due to the involvement of other pathogens such as Mycobacterium, anaerobic bacteria, virus, Mycoplasma, and fungi, and may be parasites. However, most normal lung tissues yielded one or more bacterial types even though Lopéz (2001) reported that normal lungs were ideally supposed to be sterile as the pulmonary macrophages continue to scavenge for bacterial agents in the lungs thereby making the lung free from pathogens as a defensive mechanism.

In addition to the above mentioned major bacterial pathogens, other bacterial species have been isolated from the lungs and trachea of both apparently healthy and pneumonic camels. This signifies that a number of factors may be involved in camel respiratory infections. Despite the fact that 
Micrococcus, Enterococcus, Coagulase-negative staphylococcus species, Bacillus, Proteus, Corynebacterium, E. coli, $P$. aeruginosa, and Neisseria species are considered non-pathogenic, their isolation from pneumonic camel lungs by various workers (Al-Doughaym et al. 1999; Al-Tarazi 2001; Abubakar et al. 2008; Azizollah et al. 2009; Wareth et al. 2014) indicated that they could have a role in the development of respiratory infections. Hence, the possible role of these bacteria in camel respiratory disease complex under various conditions should not be overlooked though they have not been considered as major causative agents. Very recently, an emerging Middle-East respiratory syndrome Coronavirus (MERS-CoV) has been reported in camels of the Middle East and beyond (Funk et al. 2016; Ali et al. 2017). We have also isolated a variety of viruses from respiratory tracts of Ethiopian camels (Ayelet et al. 2013). Therefore, viruses could play a significant role as a primary or complicating causative agents in camel respiratory infections.

Furthermore, the study assessed the antibiotic susceptibility profiles of the bacterial isolates in order to choose the most effective antimicrobial agents that could be used to treat camels with respiratory problems in the area. Accordingly, increased level of resistance among the respiratory pathogens against the commonly used antimicrobials in respiratory tract infections was observed (Table 2). The majority of camel respiratory pathogens were found susceptible to norfloxacin, streptomycin, and gentamicin but resistant to the action of ampicillin and tetracycline. This is in agreement with the results of El-Mahmood et al. (2009) and Serin et al. (2010). In addition, a similar resistance of $S$. equi subsp. equi and $K$. pneumoniae to tetracycline was recorded (Nkang et al. 2009). Fazlani et al. (2006) reported a high level of resistance of M. haemolytica and P. multocida to streptomycin. In this study, however, both organisms were found to be susceptible to streptomycin, while they were resistant to tetracycline and ampicillin. This represents a shift of resistance from streptomycin to tetracycline and ampicillin. This may be associated with the present lesser usage or misuse of streptomycin for animal diseases unlike tetracycline which is commonly used for most animal diseases today.

The high rate of resistance observed in many of the isolates to tetracycline and ampicillin could be either because they are frequently and unnecessarily prescribed or sold over the counter in the open market and private veterinary drug shops without prescription. The people in the study areas have easy access to purchase tetracycline and ampicillin from the private pharmacies and any open market without prescription. They have also the opportunity of getting many drugs from NGO's working in livestock production, but they have a strong desire to tetracycline. As a result, they provide health care by themselves. This probably means that the selective pressure of these commonly used antibiotics on the bacteria circulating in the community could have resulted in high frequency of resistance among the isolates. Apart from ease of accessibility, these drugs have been found to be adulterated and therefore used at a very low dosage. Therefore, there is a need for practitioners and researchers to be aware of the bacterial flora of the camels and of their antibiotic sensitivities so as to be informed of the appropriate antibiotics to be used in the course of respiratory infections and control programs.

In conclusion, the present and previous studies in this area pointed out that respiratory infection is considered as the major cause of morbidity and mortality in camels. It is a multifactorial process among which a variety of bacterial species have been associated with respiratory problems. In the present investigation, S. equi subsp. equi, P. multocida, M. haemolytica, K. pneumoniae, S. aureus, and B. bronchiseptica have been isolated at much higher proportions from the lungs of pneumonic than the apparently healthy camels. Therefore, these bacterial spp. could be considered as candidate pathogens causing camel respiratory infections in the study area. Furthermore, the isolates have shown considerable resistance to commonly prescribed antimicrobials in the country calling for the need to conduct susceptibility testing for control of camel respiratory infections in the area. Therefore, we believe the data in this work contributes to diagnosis and control of respiratory problems in camels, which are important livestock spp. in arid and semi-arid regions in Ethiopia, in particular, and the tropics, in general.

Funding information This research project was financially supported by the subTR project entitled "Investigation on Major Camel Diseases in Ethiopia and development of intervention strategies" under the TR project of "Animal Health Improvement," granted within the 1st Thematic Research (TR) of Addis Ababa University, Ethiopia. Hence, the authors are indebted to the project for its financial support as well as the College of Veterinary Medicine and Agriculture, Addis Ababa University, and Semera Regional Veterinary Laboratory for hosting and providing all the necessary facilities for smooth and effective execution of this study.

\section{Compliance with ethical standards}

Conflict of interest The authors declare that they have no conflict of interest.

\section{References}

Abubakar, M.S., Fatihu, M.Y., Ibrahim, N.D., Oladele, S.B., Abubakar, M.B., 2008. Camel pneumonia in Nigeria: Epidemiology and bacterial flora in normal and diseased lung, African Journal of Microbiology Research, 4, 2479-2483

Ahmed, M.E., Musa, M.T., 2015. Characterization of Bacteria Isolated from Dromedary Camels Affected with Pneumonia for the First Time in Sudan, Annual Research \& Review in Biology 7(1), 6167, https://doi.org/10.9734/ARRB/2015/16744

Al-Doughaym, A.M., Mustafa, K.M., Mohamed, G.E., 1999. Aetiological study on pneumonia in camel (Camelus dromedarius) and in vitro antibacterial sensitivity pattern of the isolates, Pakistan Journal of Biological Sciences, 2, 1102-1105 
Alharbi, N.K., 2016. Vaccines against Middle East respiratory syndrome coronavirus for humans and camels, Reviews in Medical Virology, https://doi.org/10.1002/rmv.1917

Ali, M.A., Shehata, M.M., Gomaa, M.R., Kandeil, A., El-Shesheny, R., Kayed, A.S., El-Taweel, A.N., Atea, M., Hassan, N., Bagato, O., Moatasim, Y., Mahmoud, S.H., Kutkat, O., Maatouq, A.M., Osman, A., McKenzie, P.P., Webby, R.J., Kayali, G., 2017. Systematic, active surveillance for Middle East respiratory syndrome coronavirus in camels in Egypt, Emerging Microbes and Infections, 6(1):e1

Al-Tarazi, Y.H., 2001. Bacteriological and Pathological Study on Pneumonia in the One-Humped Camel (Camelus dromedarius) in Jordan, Revue d' elevage et de medicine veterinaire des pays tropicaux, 54, 93-97

Ayelet, G., Negash, W., Sisay, T., Jenberie, S., Gelaye, E., 2013. Investigation of respiratory viruses in camel slaughtered at Addis Ababa Akaki Abattoir, Ethiopia, African Journal of Agricultural Research 8 (36), 4580-4587

Azizollah, E., Bentol-hoda, M., Razieh, K., 2009. The aerobic bacterial population of the respiratory passageways of healthy dromedaries in Najaf-abbad abattoir, central Iran. Journal of Camelid Science, 2, 26-29. http://www.isocard.org

Bekele, T. 2008. Gross and microscopic pulmonary lesions of camels from Eastern Ethiopia. Tropical Animal Health and Production, $40,25-28$

Bosch, A.A.T.M., Biesbroek, G., Trzcinski, K., Sanders, E.A.M., Bogaert, D., 2013. Viral and Bacterial Interactions in the Upper Respiratory Tract, PLoS Pathog, 9(1), e1003057

Caswell, J.L., 2014. Failure of respiratory defenses in the pathogenesis of bacterial pneumonia of cattle, Veterinary Pathology, 51(2), 393-409

Central Statistical Agency (CSA) 2004. Agricultural sample survey report on livestock and livestock characteristics, 37-39

Demissie, T., Dawo, F., Sisay, T., 2014. Biochemical and Antigenic Characterization of Mannheimia, pasteurella and Mycoplasma Species from Naturally Infected Pneumonic Sheep and Goats, Bishoftu, Ethiopia, African Journal of Basic and Applied Sciences, 6 (6), 198-204

Desissa, F.G., Bojia, E.D., Ayele, G.D., 2009. Isolation and Identification of Aerobic Bacterial Flora from the Upper Respiratory Tract of Donkeys in Central Ethiopia, International Journal of Applied Research in Veterinary Medicine, 7 (4), 181-189

El-Mahmood, A.M., Isa, H., Mohammed, A., Tirmidhi, A.B., 2009. Antimicrobial susceptibility of some respiratory tract pathogens to commonly used antibiotics, Journal of Clinical Medicine and Research, 2, 135-142

Fazlani, S.A., Khan, S.A., Faraz, S., Awan, M.S., 2006. Antimicrobial susceptibility of bacterial species identified from mastitic milk samples of camel, African Journal of Biotechnology, 10, 2959-2964

Funk, A.L., Goutard, F.L., Miguel, E., Bourgarel, M., Chevalier, V., Faye, B., Peiris, J.S., Van Kerkhove, M.D., Roger, F.L., 2016. MERS$\mathrm{CoV}$ at the Animal-Human Interface: Inputs on Exposure Pathways from an Expert-Opinion Elicitation, Frontiers in Veterinary Science, 3, 88

Ismail, M., El-Deen, N.E., El-Hariri, M., 2014. Bacteriological Examination of Respiratory Tract of Apparently Healthy Camels in Egypt, International Journal of Microbiological Research, 5 (1), 65-68
Janosi, S. and Kaszanyitzki, E.J., 2003. Comparison of E-test and agardisc diffusion methods for antibiotic susceptibility testing of thermophilic Campylobacter of animal origin, International Journal of Medical Microbiology, 293, 41.

Lopéz, A., 2001. Respiratory system, Thoracic cavity, and pleura. In: M.D. McGavin, W.W. Carlton, J.F. Zachary, (eds.), Thomson's Special Veterinary pathology, 3rd Edition, (Mosby, A Harcourt health Sciences company, London), 125-191

Lozano, C., Gharsa, H., Slama, B.K., Zarazaga, M., Torres, C., 2016. Staphylococcus aureus in Animals and Food: Methicillin Resistance, Prevalence and Population Structure. A Review in the African Continent, Microorganisms; 4(1) https://doi.org/10.3390/ microorganisms 4010012

Merga, T., Sisay, T., Asseged, B., 2006. The Aerobic Bacterial flora of the Respiratory passage ways of healthy goats in Dire Dawa Abattoir, Eastern Ethiopia, Revue de Médecine Vétérinaire, 157, 84-87

Nesibu, A., Gelagay, A., Shiferaw, J., Esayas, G., Tesfaye, S., Haileleul, N., 2010. Bacteriological studies on pulmonary lesions of camel (Camelus dromedarius) slaughtered at Addis Ababa abattoir, Ethiopia, African Journal of Microbiology Research, 5, 522-527

Nkang, A.O., Okonko, I.O., Mejeha, O.K., Adewale, O.G., Udeze, A.O., Fowotade, A., Fajobi, E.A., Adedeji, A.O., Babalola, E.T., 2009. Assessment of antibiotics susceptibility profiles of some selected clinical isolates from laboratories in Nigeria. Journal of Microbiology and Antimicrobials, 1, 019-026

Parks, T., Barrett, L., Jones, N., 2015. Invasive streptococcal disease: a review for clinicians, British Medical Bulletin, 115 (1), 77-89

Poliquin, P.G., Lagacé-Wiens, P., Verrelli, M., Allen, D.W., Embil, J.M., 2015. Pasteurella species peritoneal dialysis-associated peritonitis: Household pets as a risk factor, Canadian Journal of Infectious Diseases and Medical Microbiology, 26(1), 52-5

Roger, F.L., Yigezu, L.M., Hurard, C., Faye B., 2000. Investigation of a new pathological condition of camels in Ethiopia, Journal of Camel Practice and Research, 7(2), 163-165

Roger, F., Gebreyesus, M., Libeau, G., Diallo, A., Yigezu, L., Yilma, T., 2001. Detection of antibodies of rinderpest and peste des petits ruminants viruses (Paramyxoviridae, Morbillivirus) during a new epizootic disease in Ethiopian camels (Camelusdromedarius), Revue de Médecine Vétérinaire, 152, 265-268

Serin, I., Ceylan, A., Kirkan, S., Parin, U., 2010. Preputial Bacterial Flora and Antibiotic Susceptibility in Wrestling Dromedary Bulls in Aydin Region of Turkey, Journal of Animal and Veterinary Advances, 9 (3), 482-485

Tesfaye, B., Tessema, T.S., Tefera, G., 2013. Diversity of bacterial species in the nasal cavity of sheep in the highlands of Ethiopia and first report of Histophilus somni in the country, Tropical Animal Health and Production, 45(5), 1243-9

Wareth, G., Murugaiyan, J., Khater, D.F., Moustafa, S.A., 2014. Subclinical pulmonary pathogenic infection in camels slaughtered in Cairo, Egypt, Journal of Infection in Developing Countries, 8(7), 909-913

Wernery, U., Metwalley, S., Mohamed, F., 2006. Camel disease investigation in Ethiopia: Ethiopia 8-17, January 2006. Report to Ministry of Agriculture and Rural Development

Yigezu, L.M., Roger, F., Kiredjian, M., Tariku, S., 1997. Isolation of Streptococcus equi subsp. equi (strangles agent) from an Ethiopian camel, Veterinary Record, 140, 608 